\title{
Lifestyle Factors' Impact on Sleep of College Students
}

\author{
Campsen NA* and Buboltz WC \\ Department of Psychology and Behavioral Sciences, \\ Louisiana Tech University, LA, USA
}

*Correspondling author: Campsen NA, Department of Psychology and Behavioral Sciences, Louisiana Tech University, Ruston, LA, USA

Received: February 21, 2017; Accepted: March 01, 2017; Published: March 03, 2017

\begin{abstract}
Transitioning to college is often met with distinct lifestyle factors that differ from those individuals who do not make such a transition. Such factors include alcohol consumption, caffeine consumption, psychostimulant use, dietary habits, class schedules, and physical activity. These lifestyle factors may impact the sleep length and quality of college students, which leads to other outcomes. Research has explored the relationship between some of these factors and sleep among college students with mixed results. The purpose of this study was to examine the relationship between several lifestyle factors of college students and their impact on the length and quality of sleep. Results indicated that food choice and physical activity are significantly related to sleep quality. Additionally, the amount of caffeine consumed was determined to be related to sleep quality. For sleep length, both amount of caffeine consumed and average hours worked per week were related to sleep length. Although some factors were determined not to predict sleep quality or sleep length, results indicated that there are several specific lifestyle factors associated with being a college student that impact sleep length and sleep quality. Thus, colleges and universities should evaluate the amount and quality of sleep of their students.
\end{abstract}

Keywords: College students; Lifestyle factors; Sleep quality; Sleep length

\section{Introduction}

Sleep can be best defined by two components: length and quality. Sleep length refers to the amount of sleep one gets per night. Sleep quality, as defined by the National Sleep Foundation [1], is one's own satisfaction with their sleep experience. This includes sleep initiation (starting of sleep), sleep maintenance (tossing and turning; waking up throughout the night), sleep quantity (amount of sleep), and the feeling of refreshment upon awakening [1]. According to the National Institutes of Health: National Heart, Lung, and Blood Institute [2], a sufficient amount of sleep is necessary to maintain mental and physical health. Adolescents, despite getting an adequate amount of sleep, traditionally have increased daytime sleepiness and a greater necessity for sleep compared to prepubescent children [3]. A decrease in the length and quality of sleep an adolescent receives also becomes problematic in terms of general health and overall well-being.

The sleep we are able to get allows for our brain to function properly, allowing for us to learn, pay attention, make decisions, and be creative throughout the day [2]. Research has also found a relationship between sleep and academic performance. Those students who have been found to have lower overall grades also had later bed and wake times than those students who had been found to have higher overall grades $[4,5]$. It has also been determined that sleep is related to working memory, long-term memory, and memorization stages including encoding, consolidation, and reconsolidation $[6,7,8]$. Poor sleep quality has also been found to contribute to a variety of health issues, such as somatic stress $[9,10]$. Research has found that those who obtain poor sleep require more time to complete tasks, have a slower reaction time, and make an increased number of mistakes [2]. Despite such findings, research has consistently found that college students do not receive an adequate amount of sleep or good sleep quality.

\section{Length and quality of sleep amongst college students}

As recommended by the National Sleep Foundation [1], younger adults should receive seven to nine hours of sleep per night. However, due to an increase in demands, the quality and length of sleep a college student obtains becomes especially problematic when older adolescents make the transition into college. In a previous study, college students reported receiving consistently limited amounts of sleep, noting particular problems with receiving adequate sleep on weeknights [11]. On average, college students have reported sleeping about an hour longer on the weekends than on weekdays [12]. College students have endorsed fewer hours of sleep on weekdays than on weekends, noting oversleeping on most weekends [11-13]. Lund et al. found that college students, on average, were sleeping approximately seven hours, while $25 \%$ of students in that sample reported sleeping less than 6.5 hours a night and only $29.4 \%$ reported sleeping eight or more hours a night. In respect to gender, male college students also reported significantly later bed and rise times than their female counterparts [11]. Similarly, Buboltz et al. (2009) determined that, on average, participants were sleeping about 7 and a half hour per night, while sleeping over 8 hours on the weekend.

Previous research has indicated that college students have consistently reported poor sleep quality as well. For example, Lund et al. (2009). found that $38 \%$ of their participants reported poor quality sleep, specifically indicating that restricted total sleep time, long sleep latencies, and low enthusiasm were the most common factors contributing to such poor quality sleep. Those students indicated lacking enthusiasm to complete things at least once a week, being unable to fall asleep within 30 minutes at least once a week, stress, excess noise, and co-sleeping as contributing factors to their poor sleep quality [11]. Additionally, $70 \%$ of college students in one sample reported that their amount of sleep during the week was not 
nearly or not quite enough and $48 \%$ of the same sample reported experiencing sleep difficulties occasionally or always during the week [12]. Similarly, Kenney et al. (2014) found that $53.8 \%$ of their sample experienced poor sleep quality.

Buboltz et al. (2009) also found that a higher percentage of college students needed more than 30 minutes to fall asleep, experienced disturbed sleep three or more nights a week, experienced nocturnal awakening most nights, woke up too early three or more nights a week, and used sleep medications weekly. Also, it was determined that $11.1 \%$ of the participants reported experiencing insomnia three or more times a week [11]. Additionally, Forquer et al. (2008) found that the time delay for $33 \%$ of the participants to fall asleep was more than 30 minutes, while $43 \%$ of the participants reported waking up more than once during the night. Lund et al. (2010) found similar results, in that $32 \%$ of the college students who participated in the study reported being unable to fall asleep for at least 30 minutes.

\section{Outcome of poor sleep quality and length}

With an understanding that poor sleep quality and sleep length is a common occurrence amongst college students, it is important to understand the ways in which such sleep impacts college students Hershner and Chervin (2014) found that sleepiness in college students negatively impacts their learning abilities, memory, academic performance, mood, driving performance, and their perception of their effort. Previous research has also found that college students that receive less than the average amount of sleep were more likely to have an occurrence of depressive symptoms two weeks following the deprivation of sleep [16]. College students with poorer sleep quality have also reported significantly higher negative moods [11]. Additionally, college students reporting poor quality sleep also reported significantly more physical illness in comparison to those students who reported ideal and close-to-ideal sleep quality [11]. Previous research has also found that college students who had reported experiencing anxiety or depression during the academic year also reported poorer sleep quality [17].

Previous research has also found that poorer sleep quality is associated with lower academic performance. Nondepressed college students who reported poor sleep quality also reported lower academic performance [18]. Gomes, Tavares, \& de Azevedo (2011) found similar results in that those college students who reported poorer sleep quality and those college students who reported lower frequency of an adequate amount of sleep also perceived their sleep patterns to negatively impact their academic performance. Previous research has also found that those college students who have earlier bed times and earlier wake times also have higher Grade Point Averages (GPA) in comparison to those college students with later bed and wake times [4].

\section{Lifestyle factors of college students}

Prior to entering college, a majority of students were codependent on their caretakers to make most important decisions. College students are required to make decisions regarding things such as class times, bed and rise times, dietary intake, times for physical activity, participation in social organizations or other activities on campus, and whether or not to engage in the adventurous lifestyle that exists on most college campuses [19]. With a need for balance among priorities in a college student's schedule, there is often neglect of some life aspects.

College students have been known to depend on such substances as coffee, caffeinated beverages, psychostimulants, and energy drinks to improve performance and concentration [20-23]. While college students are frequently prescribed psychostimulants for the treatment of Attention Deficit Hyperactivity Disorder (ADHD) symptoms, other college students have reported consuming such substances non-medically and non-prescribed in order to improve concentration, to improve alertness, or to remain awake [21,23]. Also, energy drink consumption has become a popular practice among college students $[20,22,24]$. College students have frequently endorsed the use of energy drinks as a way to compensate for loss of sleep, while completing academic work, and to alleviate high levels of stress $[20,22]$.

Alcohol consumption is an area of relevance when attempting to understand the lifestyle of a college student and their sleep habits. College students have reported an increased tendency to consume alcohol when living on campus, when introduced to drinking alcohol by peers, and when individuals have been enrolled in college for a longer period of time [25]. Alcohol consumption also impacts dietary habits of college students, with college students limiting their calorie intake in order to become more intoxicated or to avoid becoming sick while drinking alcohol [26,27]. Also, previous research has found that college students who reported consuming alcohol are more likely to also report oversleeping and staying awake later on the weekends than on weekdays $[28,29]$. More specifically, college students who reportedly consumed larger amounts of alcohol reported less nighttime sleep, later sleep schedules, and greater delays between weekday and weekend bedtimes [29].

College students' dietary choices typically differ from student to student. Many students have endorsed such influences as their current living situation, class and social activity schedules, peer influences, ease of access and availability of food options, and the appeal of the food as determinants for their daily food choices [30]. Other research has also found college students who engage in smoking, alcohol consumption, and reduced physical activity reported poor dietary habits as well [31]. Participation in physical activity amongst college students largely depends on self-motivation, time management, lack of availability of time, transition to college, fear of embarrassment, and whether or not they participate in sports organizations [32]. College students have previously indicated that they comprehend the need for and the benefits of physical activity, but often times determine it to be difficult to find time for exercise during their busy schedules, feel inadequate, or lack peer motivation $[32,33]$.

\section{Lifestyle factors of college students and their impact on sleep}

College students are frequently associated with lifestyle factors that are usually less common in the general population. College students are faced with a new and unfamiliar level of freedom. While most individuals are faced with balancing schedules and participating in social events on a daily basis, college students are usually introduced to independence for the first time and are forced to tackle such situations on their own without any guidance from parents or other caretakers [19]. This type of situation can have a negative impact on a college student's ability to meet expectations that has been set before 
them. Often times, a need to fulfill such expectations begins to take a negative toll on the amount and quality of sleep they get every night. This is evidenced in delay of sleep and all nighters that are sometimes pulled by college students in order to complete necessary projects. Sleep may be seen as something that can be made up for at a later time.

Additionally, college students have reported experiencing a decrease in sleep quality during the month of an important exam [34]. College students have also reported a decrease in sleep length and sleep efficiency, as well as an increase in the latency of sleep onset and daytime sleepiness, around the time of an exam [34]. Such findings are concerning, noting that previous research has also found that poorer sleep quality is associated with poorer academic performance [18]. Understandably, academic stress in college can result in a decrease in sleep quality and sleep length, which in turn can negatively impact academic performance.

Typically, college students do not have much input in regards to the times at which classes are offered or when social organizations meet or sports teams practice. As a result, college students often arrange their sleep schedules around their class schedules. Research has found that those students who have classes that start at later times in the day also have later bed and rise times, as well as less daytime sleepiness as a result [35]. As a college student, it is not uncommon to also maintain a job while attending school. However, maintaining a job while attending school can impact the sleep of a working college student. College student workers go to bed earlier and wake up earlier in comparison to non-working students [36]. As indicated by previous research, student workers reportedly received shorter sleep length in comparison to non-student workers [36]. Similar results were found in a separate study, noting that students who worked and studied in the evening woke up earlier and also reported fewer hours of sleep in comparison to those students who did not work [37]. It was also found that all the participants in the study, despite having a job, engaged in delayed sleep during the weekends, noting that those who preferred mornings and had no job reported the greatest delay [37]. Despite this, students who were employed went to sleep at the same time on the weekdays and weekends [37]. Overall, it is understood that the schedules in which a college student follows (class or work) help determine the times at which that student goes to bed and wakes up each day.

Understanding that alcohol use is common among the college student population, research has also examined the impact of alcohol on the length and quality of sleep of college students. Alcohol use amongst college students has been found to have a negative relationship with the amount of sleep college students receive due to a later bedtime, often resulting in an increase in daytime sleepiness and poor academic performance [14,29]. Specifically, Kenney et al. (2014) found that those college students who endorsed alcohol consumption as a personally regarded form of coping also reported poorer quality of sleep than those who endorsed lower coping motives for consuming alcohol.

Consequently, previous research has also found a significant relationship between non-medical and non-prescribed psychostimulant use and sleep quality of college students. Previous research has found that those students who endorsed non-medical use of prescription stimulants reported using such medications as a way to improve concentration, to improve alertness, to remain awake, or to achieve a high $[21,23]$. Despite this, research has found that such use of prescription stimulants resulted in a significant decrease in subjective sleep quality, an increase in sleep disturbances, and poor global sleep quality [38].

Previous research, with a sample of college freshmen, found that students reported consuming a mean amount of $849.84 \mathrm{mg}$ of caffeine a day, which is approximately three times the recommended amount of the Mayo Clinic $[39,40]$. Additionally, energy drink consumption among college students has also been found to be of significance, with $51 \%$ of college students reporting consuming more than one energy drink each month during the semester [20]. The use of energy drinks has been found to negatively impact sleep quality and sleep duration and is sometimes used to counteract sleepiness in college students $[20,29,38]$. Additionally, Lohsoonthorn et al. (2013) found that those college students who reported consuming two or more stimulant beverages per week also reported poorer sleep quality in comparison to those students who reported only consuming one stimulant beverage per week.

Dietary habits of college students also fluctuate and are typically impacted by frequent restaurant visits, an increased consumption of fast food and convenience food, and a decrease in the amount of meals prepared in the home. Research has found that college students who experience sleep deprivation also displayed a decrease in calorie consumption [42]. Additionally, the reason for which students chose particular food also changed with sleep deprivation [42]. Those college students who experienced sleep deprivation chose foods less on the basis of health concerns, sensory appeal, price, natural content, familiarity, sensory appeal, and ethical concern [42]. However, food choice based on mood and convenience remained unchanged [42]. As a result, it seems possible that when experiencing sleep deprivation, college students may choose less healthy foods in comparison to those students who receive an appropriate amount of sleep [42]. Research has also found that limited time, as a result of sleep schedules, has minimized the frequency of having breakfast for college students [31]. This type of behavior has also been found to have a significant relationship with the amount of exercise in which college students engage in, as well as the amount of caffeine-containing beverages college students may consume in a day [31].

Physical activity is often considered a component in overall wellness and is necessary in order to remain active and healthy [43]. Research has found that regular exercise improves sleep length, sleep quality, reduced sleep onset delay, and improved sleep efficiency, college students often overlook physical activity and exercise as an area of importance [43]. Wu et al. (2015) found that with an increase in physical exercise, college students expressed an increase in protective measures regarding depression, psychopathological symptoms, and poor sleep. Previous research has also argued that those college students who do without breakfast, usually as a result of an inadequate amount of sleep, are less likely to participate in physical activity [31]. It has also been found that with eating breakfast there is an increase in energy, which in turn is considered to positively impact the amount of physical activity a college student participates in [45]. 


\section{The Present Study}

The purpose of this study is to examine the relationship between lifestyle factors of college students and length and quality of sleep of college students. It was hypothesized that 1) college students with poor dietary habits will have significantly poorer sleep quality and shorter length of sleep, 2) college students with higher caffeine consumption will have significantly shorter sleep length and poorer sleep quality, 3) college students with higher stimulant use will have significantly poorer sleep quality and shorter length of sleep, 4) college students' class times will be significantly related to sleep quality and length such that students with later class times will have significantly poorer sleep quality and shorter sleep length, 5) lower levels of physical activity among college students will be significantly related to poorer sleep quality and shorter length of sleep, 6) college students with higher alcoholic beverage consumption will have a significantly poorer sleep quality and shorter length of sleep, and 7) college students with greater number of hours reportedly worked per week will have significantly shorter sleep length and poorer sleep quality.

\section{Method}

\section{Participants}

There were 416 college students from a southern university who participated in this study. The mean age of the sample was 19.86 (SD $=4.11$ ). A majority of the sample was $61.5 \%$ females and Caucasian $(73.8 \%)$. The mean GPA of participants was $3.42 \%(S D=1.44)$. A majority of the sample were freshmen $(51.0 \%)$ and sophomores $(28.6 \%)$.

\section{Measures}

Demographics. A demographic questionnaire asked individuals to provide information regarding their age, gender, academic status and major, Grade Point Average (GPA), ethnicity, and hours employed outside of school.

Substance/Caffeine use. Individuals were asked to indicate yes or no in response to questions regarding their alcohol, tobacco, caffeine, and stimulant use. They were also asked to provide information regarding the average amount of each substance used per use.

Daily activity schedule. Individuals were asked to report wake times, meal times (including snacks), class times, times of participation in any outside school activities, and any other participation in physical exercise on a seven-day calendar with time slots for each day from 7 A.M. to 2 A.M. They were asked to indicate the times that they participated in any activities across the seven days of the week by marking such time on the provided schedule. Those students who reported that a majority of their classes and other activities are scheduled between the hours of 7 A.M. to 12 P.M. were classified as morning students. Those students who reported that a majority of their classes and other activities are scheduled between the hours of 12 P.M. and 5 P.M. were classified as evening students.

Pittsburgh Sleep Quality Index (PSQI). The PSQI [46] is a selfreport questionnaire that assesses sleep quality and sleep disturbances over a month. It contains 19 items rated on a 4-point Likert scale [46]. The questionnaire consists of seven subscales [46]. The present study focused specifically on the individuals' responses to item 4 , which specifically inquires, "During the past month, how many hours of actual sleep did you get at night?"

Adult Sleep Wake Scale (ADSWS). The ADSWS [47] is a selfreport measurement of adult sleep quality. It has five dimensions that measure behaviors related to sleep including: going to bed, falling asleep, maintaining sleep, reinitiating sleep, and returning to wakefulness [47]. It contains 25 items on a 6-point Likert type scale [47]. Scores from the subscales are totaled to determine a global sleep quality score, which ranges from 0-30 points [47]. Higher scores on the measure are indicative of poor sleep quality. For the present study, the global score was employed.

Food Choice Questionnaire (FCQ). The FCQ [48] is a 36-item self-report questionnaire that measures factors that influence people's dietary choices. It consists of nine subscales [48]. The items are on a 6-point Likert type scale [48]. Higher scores on the instrument indicate sensitivity to emotional conditions, external cues, and greater restraint [48].

Physical activity questionnaire for adults (PAQ-AD). The PAQ$\mathrm{AD}[49]$ is a 8-item adult version of the Physical Activity Questionnaire for Older Children (PAQ-C) and the Physical Activity Questionnaire for Adolescents (PAQ-A). It is a self-report questionnaire that measures the physical activity of adults [49]. The items are scored on a 5-point Likert scale [49]. In order to obtain a composite score, the mean score for question 1 is calculated and then added with the mean scores of questions 2 through 7 to get a total score [49]. A total score of 5 for questions 1 through 7 is representative of high activity and a score of 1 for questions 1 through 7 represents low activity [49]. An eighth item is also included in order to consider if sickness or other events may have prevented normal physical activities, but is not used in the calculation of the total score [49].

\section{Procedure}

Participants were recruited from psychology and education courses from a southern, mid-sized university and were given a brief review of the study and potential incentives for participation, including earning extra credit if allowed by the instructor. Questionnaire packets were distributed to individuals who volunteered to take part in the study. Included in the packet was an informed consent form that participants signed, which was detached upon completion of the questionnaire packet.

\section{Results}

\section{Data analysis}

Data were screened for outliers and any missing data, with those cases exceeding $10 \%$ of missing values being removed. The method of mean substitution was used in order to handle missing values of those items not related to demographic information [50]. Upon initial analysis, it was determined that there were three outliers within the data set, which were removed. Assumptions for each analysis were assessed and followed through accordingly.

\section{Descriptive statistics}

The present study found that $39.9 \%$ of participants reportedly slept less than 7 hours on average per night. The participants in the study reported, on average, 6.89 hours of sleep. Participants in the present study, on average, scored a 78.15 on the Adult Sleep Wake Scale. Higher scores on this measure indicate poorer sleep quality 
Table 1: Lifestyle Factors, Sleep Quality, and Sleep Length: Correlations and Descriptive Statistics.

\begin{tabular}{|c|c|c|c|c|c|c|c|c|c|}
\hline Variables & 1 & 2 & 3 & 4 & 5 & 6 & 7 & $M$ & $S D$ \\
\hline Sleep Quality & - & & & & & & & 79.1 & 18.87 \\
\hline Sleep Length & $-.309 * \star$ & - & & & & & & 6.89 & 1.23 \\
\hline Caffeine & $.148^{\star \star}$ & $-.140^{\star}$ & - & & & & & 7.57 & 5.21 \\
\hline Stimulant & -0.04 & 0.098 & -0.04 & - & & & & 17.4 & 20.21 \\
\hline Physical Activity & $-.109 *$ & -0.01 & -0.05 & -0.04 & - & & & 2.12 & 0.8 \\
\hline Alcohol & -0.123 & -0.06 & 0.135 & $.434^{\star *}$ & 0.013 & - & & 2.23 & 2.57 \\
\hline Hours Worked & 0.078 & $-.148^{\star \star}$ & $.201^{\star *}$ & 0.112 & -0.02 & 0.1 & - & 10.3 & 12.35 \\
\hline
\end{tabular}

Note: $N=416{ }^{*} p<.05 .{ }^{* *} p<.01$.

[47]. With a majority of the sample being freshmen and sophomores, differences between their sleep quality and average sleep length were examined. There was an increase in sleep quality scores from the freshmen group $(M=77.49, \mathrm{SD}=17.34)$ to the sophomore group $(M$ $=79.41, S D=20.70)$, which was not statistically significant $(p=.897)$. Additionally, there was an increase in sleep length from the freshmen group $(M=6.80, S D=1.26)$ to the sophomore group $(\mathrm{M}=7.12$, $\mathrm{SD}$ $=1.29)$, which was not statistically significant $(p=.171)$. Results of the present study also indicated that participants reported consuming 12.98 ounces of alcoholic drinks $(\mathrm{SD}=1.946)$ on average per week. Participants reported consuming, on average, 25.09 ounces of caffeinated beverages $(S D=20.58)$ per week. Of the total participants, 72 participants indicated consuming stimulants during the week, with 59 participants consuming, on average, $21.93 \mathrm{mg}$ of stimulants per day. Participants indicated working on average 10 hours $(\mathrm{SD}=$ 12.35) per week while attending school.

\section{Hypothesis 1}

Regression analysis was conducted to evaluate the relationship between food choice and sleep length and sleep quality. The results of the regression analysis indicated that overall food choice accounted for $3.1 \%$ of the variance in sleep length and was not significant, $\mathrm{R}^{2}$ $=.031$, Adjusted $\mathrm{R}^{2}=.010, F(9,412)=1.441, p=.168$. The results of the regression analysis also indicated overall food choice accounted for $7.3 \%$ of the variance in sleep quality and was significant, $\mathrm{R}^{2}=$ .073 , Adjusted $\mathrm{R}^{2}=.053, F(9,406)=3.556, p<.001$. Examination of the regression coefficient indicated that food choice related to the prevention of chronic disease and to overall nutrition (Health Scale) $(B=-9.122, \beta=-.363, p<.001,95 \%$ CI $[-13.100,-5.144])$, general alertness and mood (Mood Scale) $(B=3.374, \beta=.141, p=.027$, $95 \%$ CI $[.395,6.352])$, and weight control (Weight Control Scale) (B $=-.537, \beta=.139, p=.0 .39,95 \%$ CI $[.161,6.186])$ significantly and positively predicted sleep quality.

\section{Hypothesis 2}

A Pearson's product-moment correlation was run to assess the relationship between average amount of caffeine consumed and sleep length and sleep quality. There was a significant negative correlation between average amount of caffeine consumed and sleep length, $r(305)=-.140, p=.014$ (Table 1 ). There was also a significant positive correlation between average amount of caffeine consumed and sleep quality, $r(305)=.148, p=.009$ (Table 1). With lower scores indicating better sleep quality, it was determined that as amount of caffeine consumed decreases, sleep quality and sleep length increases [47].

\section{Hypothesis 3}

A Pearson's product-moment correlation was run to assess the relationship between average dosage of simulant reportedly consumed and sleep length and sleep quality. Results showed that there was no significant relationship between average dosage of simulant reportedly consumed and sleep length, $r(56)=-.098, p=$ .467 (Table 1). There was also no significant relationship between average dosage of simulant reportedly consumed and sleep quality, $r(56)=-.040, p=.768$ (Table 1$)$.

\section{Hypothesis 4}

A one-way ANOVA was conducted to determine if sleep length or sleep quality was different for college students in relation to their class schedule. There were no statistically significant differences in sleep length between those students who were classified as morning students and those classified as afternoon students, Welch's $F(1$, $232.94)=.247, p=.620$. There was no significant difference between sleep quality for morning students and the evening students, $F(1,373)$ $=.118, p=.731$.

\section{Hypothesis 5}

A Pearson's product-moment correlation was run to assess the relationship between physical activity and sleep length and sleep quality. It was determined that there was no relationship between physical activity and sleep length, $r(416)=-.007, p=.886$ (Table 1 ). There was a small, negative correlation between physical activity and sleep quality, $r(416)=-.109, p=.027$ (Table 1). With lower scores indicating better sleep quality, it was determined that as physical activity increases, sleep quality increases [47].

\section{Hypothesis 6}

A Pearson's product-moment correlation was run to assess the relationship between average amount of alcoholic beverages reportedly consumed and sleeps length and sleep quality. It was determined that there was no relationship between average amount of alcoholic beverages reportedly consumed and sleep length, $r(183)$ $=-.062, p=.402$ (Table 1). There was no significant relationship between average amount of alcoholic beverages reportedly consumed and sleep quality, $r(183)=.123, p=.096$ (Table 1). However, results indicated a small, significant positive relationship between average amount of alcoholic beverages reportedly consumed and going to bed, $r(183)=.173, p=.019$.

\section{Hypothesis 7}

A Pearson's product-moment correlation was run to assess the relationship between average amount of hours reportedly worked per 
week and sleeps length and sleep quality. There was a small, negative correlation between average amount of hours reportedly worked per week and sleep length, $r(402)=-.148, p=.003$ (Table 1). This indicated that as the average amount of hours worked increases, sleep length decreases. There was no correlation between average amount of hours reportedly worked per week and sleep quality, $r(402)=$ $.078, p=.120$. However, there was a small and positive correlation between average amount of hours reportedly worked per week and sleep quality specifically related to reinitiating sleep, $r(402)=.117, p$ $=.019$ (Table 1$)$.

\section{Discussion}

Overall, there has been a consistent trend in prevalence statistics supporting that college students report short sleep length and poor sleep quality [12]. Although the National Sleep Foundation [51] recommends that college students should obtain seven to nine hours of sleep, the present study indicated that participants were sleeping, on average, less than seven hours per night, indicating that college students are consistently reporting difficulty obtaining the recommended length of sleep.

The results of the present study indicated that although overall food choice was not significantly related to sleep length, it was found to be significantly related to sleep quality. Further examination indicated that food choice specifically related to health, mood, and weight control significantly and positively predicted sleep quality. It appears that poor sleep quality leads to making food choices different from when an individual is sleeping better.

Additionally, results also indicated that the average amount of caffeine reportedly consumed was significantly, negatively related to sleep length. Findings indicate that with an increase in caffeine consumption, there is a decrease in sleep length [20,22,24]. Results indicated that as the amount of caffeine consumed increases, sleep quality decreases, which supports findings of previous research [41]. As indicated by the results, college students who engage in caffeine consumption are likely to have a negative impact on their sleep and academic performance.

Results of also indicated that there was no significant relationship between average dosage of stimulant reportedly consumed and sleep length and quality. Although findings do not indicate any significant relationship between stimulant use and sleep, findings may be misleading due to a low number of participants acknowledging stimulant use.

Results indicated that as the number of hours worked per night increased, the number of hours slept per night decreased, which is similar to those found by previous research [37]. What this indicates is that college students who work experience a decrease in amount of sleep they get per night. No relationship was found between average amount of hours reportedly worked per week and overall sleep quality, however, there was a relationship between average amount of hours reportedly worked per week and reinitiating sleep. This indicated that those college students who are working are also experiencing constant awakening throughout the night and having difficulty with falling back asleep.

Additionally, results of the present study indicated that there was no statistically significant differences in sleep length or quality between those students who were classified as morning students and those classified as evening students. The reason for such findings may be due to the fact that no one group is experiencing poorer sleep quality when compared to the other, but may be generally experiencing poorer sleep quality.

Results indicated that as the amount of physical activity engaged in increases, overall sleep quality improves. Such findings are consistent with previous research indicating that increased physical activity leads to improved sleep quality [43]. Results, however, indicated that there was no relationship between physical activity and sleep length. Although increased physical activity appears to lead to improved sleep quality, it does not appear to increase the amount of sleep per night one receives. For college students, an increase in physical activity will improve the satisfaction and quality of sleep one gets, which may in turn improve academic performance.

In relation to average amount of alcoholic beverages reportedly consumed, there was no significant relationship between average amount of alcoholic beverages reportedly consumed and sleep quality. However, there was a relationship between average amount of alcoholic beverages reportedly consumed and sleep quality specifically related to going to bed. As research has indicated, college students who have reported consuming large amounts of alcohol have also indicated that they experience delays in sleep [29]. Results also showed that there was no significant relationship between average amount of alcoholic beverages reportedly consumed and sleep length, indicating that the average amount of alcoholic beverages consumed does not impact sleep length. This may be due to the time at which one drinks or whether or not they consume alcohol regularly.

\section{Implications}

Results from the present study indicated that college students are consistently experiencing difficulties in regards to achieving quality sleep, indicating that there is still room in the field of sleep research to continue to investigate the ongoing phenomenon of poor sleep quality and short sleep length amongst college students. Although all results did not indicate significant findings, the results do provide information in regards to the lifestyle factors of college students. Findings of the present study indicated that college students prefer food that appeals to their senses, is convenient, and is within a good price range. Results of the present study also support the notion that alcohol use is common amongst the college student population. Although alcohol use was determined to not be significantly related to either sleep length or sleep quality in the present study, previous research has determined that alcohol use can impact caloric intake of college students [26,27]. The present study also indicated that average caffeine consumption is significantly related to both sleep quality and sleep length. Additionally, college students in the present study endorsed maintaining employment outside of school.

With the results of the present study, psychologists and other counselors should strive to gain an understanding of the quality and length of sleep their college student client may be receiving. With these results, it would be important for universities and colleges to move towards providing psychoeducation in regards to the importance of good sleep. Education in regards to how poor sleep can impact their academic performance, as well as education in regards to what can 
impact their sleep, should be provided by the universities and colleges in order to curtail the negative impact of poor sleep quality and sleep length. Such education could decrease the engagement in lifestyle factors that negatively impact sleep quality and sleep length.

This information provided by the present study is also important in providing students with the most beneficial food items on campus. Understanding that weight gain is common amongst the college student population, universities and colleges should strive to provide food that fulfills the students' needs. Also, universities and colleges should consider educating college students in regards to responsible alcohol use. Psychologists and other counselors should focus on educating their clients, rather than implying that alcohol use is nonexistent amongst college students. Such education could curtail the negative impact alcohol use can have on academic performance, sleep, and overall health.

Universities and colleges should also provide information regarding caffeine consumption and the ways in which it can impact their sleep, as well as their academic performance. With a healthy understanding of caffeine use, college students may move towards a better balance of non-caffeinated and caffeinated beverages in order to decrease such negative impacts. Also, when working with college students, psychologists and counselors should provide this important information to their clients as well. Understanding caffeine use exists regardless of such education, it is important to discuss with college students the ways in which they can find a more healthy balance. As indicated by the present study, it is not uncommon for college students to maintain employment. Not all students can afford to attend school without working. For this reason, it would be important for faculty or advisors to include such information when advising a student in regards to the classes they should take. For this reason, it appears necessary for universities and colleges to also discuss with students ways in which they can balance both the working and student aspects of their lives.

\section{Limitations}

The present study had several limitations that contributed to the results. One such limitation is that the participant sample was collected from one university located in the Southeastern portion of the United States and consisted of a majority of undergraduate students. As a result, it is unclear if geographic location contributed to the results of the study. It is also not possible to generalize the findings in the present study to other college students. The use of one university in one geographic location may have limited the diversity in the sample.

A second limitation of the present study was the self-report nature of the measures used. The third limitation of the present study was the open-ended nature of the questions related to caffeine, stimulant, and alcohol use, as well as hours worked per week. The information provided may not have been accurate as a result of both such limitations. For this reason, participants may not have been honest in regards to their responses. Instances of over reporting and underreporting of information may be possible. Understanding that such measures would be turned into their instructors and would be viewed by the primary researcher may have influenced their willingness to openly provide information.

\section{Future Research}

This particular study looked at specific lifestyle factors that only make up a small portion of a college student's life. For this reason, future research should expand upon other lifestyle factors that make up a college student's life, such as extracurricular activity participation, what time of the day do they eat, how many meals do they eat each day, etc. Additionally, in regards to sleep quality, the present study only used the scores provided by the Adult Sleep Wake Scale [47]. For this reason, future research should also look to examine sleep quality through the use of other measures. The nature in which sleep length was evaluated in the present study was through the use of one question included in the Pittsburgh Sleep Quality Index [46]. Future research should consider broadening the way in which sleep length is evaluated.

Although the present study focused on lifestyle factors that have been supported by research as existing, there are other contributing factors that impact an individual's sleep patterns. For this reason, future research should focus on mood related factors and psychological factors that may also be impacting the sleep quality and sleep length of college students. The findings of the present study are a compiled beginning to understanding the role of multiple factors of a college student's lifestyle and how they impact sleep quality and sleep length. Future research may also seek to determine if the present study's findings are applicable to other universities. Future replication studies should look to expand the geographic location at which the data are collected and look to include a more diverse sample.

\section{References}

1. National Sleep Foundation. Sleeptionary: Definitions of common sleep terms. 2016.

2. National Institutes of Health: National Heart, Lung, and Blood Institute. Why is sleep important? 2015.

3. Carskadon MA, Harvey K, Duke P, Anders TF, Litt IF, Dement WC. Pubertal changes in daytime sleepiness. Sleep: Journal of Sleep and Sleep Disorders Research. 1980; 2: 453-460.

4. Eliasson AH, Lettieri CJ, Eliasson AH. Early to bed, early to rise! Sleep habits and academic performance in college students. Sleep and Breathing. 2010; 14: 71-75.

5. Wolfson AR, Carskadon MA. Sleep schedules and daytime functioning in adolescents. Child Development. 1998; 69: 875-887.

6. Kopasz M, Loessl B, Hornyak M, Riemann D, Nissen C, Piosczyk H, Voderholzer U. Sleep and memory in healthy children and adolescents - a critical review. Sleep Medicine Reviews. 2010; 14: 167-177.

7. Van Dongen HP, Maislin G, Mullington JM, Dinges DF. The cumulative cost of additional wakefulness: Dose-response effects on neurobehavioral functions and sleep physiology from chronic sleep restriction and total sleep deprivation. Sleep: Journal of Sleep and Sleep Disorders Research. 2003; 26: 117-126.

8. Walker MP, Stickgold R. Sleep, memory, and plasticity. Annual Review of Psychology. 2006; 57: 139-166.

9. Costa G. Shift work and occupational medicine: An overview. Occupationa Medicine. 2003; 53: 83-88.

10. Holbrook AM, Crowther R, Lotter A, Cheng C, King D. Meta-analysis of benzodiazepine use in the treatment of insomnia. CMAJ: Canadian Medical Association Journal. 2000; 162: 225-233.

11. Lund HG, Reider BD, Whiting AB, Prichard JR. Sleep patterns and predictors of disturbed sleep in a large population of college students. Journal of Adolescent Health. 2010; 46: 124-132. 
12. Buboltz W, Jenkins SM, Soper B, Woller K, Johnson P, Fans T. Sleep habits and patterns of college students: An expanded study. Journal of College Counseling. 2009; 12: 113-124.

13. Forquer LM, Camden AE, Gabriau KM, Johnson CM. Sleep patterns of college students at a public university. Journal of American College Health. 2008; 56: 563-565.

14. Kenney SR, Paves AP, Grimaldi EM, LaBrie JW. Sleep quality and alcoho risk in college students: Examining the moderating effects of drinking motives. Journal of American College Health. 2014; 62: 301-308.

15. Hershner SD, Chervin RD. Causes and consequences of sleepiness among college students. Nature and Science of Sleep. 2014; 6: 73-84.

16. Brooks PR, Girgenti AA, Mills MJ. Sleep patterns and symptoms of depression in college students. College Student Journal. 2009; 43: 464-472.

17. Orzech KM, Salafsky DB, Hamilton LA. The state of sleep among college students at a large public university. Journal of American College Health. 2011; 59: 612-619.

18. Gilbert SP, Weaver CC. Sleep quality and academic performance in university students: A wake-up call for college psychologists. Journal of College Studen Psychotherapy. 2010; 24: 295-306.

19. Vaez M, LaFlamme L. Experience stress, psychological symptoms, self rated health and academic achievement: A longitudinal study of Swedish university students. Social Behavior and Personality. 2008; 36: 183-196.

20. Malinauskas BM, Aeby VG, Overton RF, Carpenter-Aeby T, Barber-Heidal K. A survey of energy drinks consumption patterns among college students. Nutrition Journal. 2007; 6: 35 .

21. McCabe SE, Knight JR, Teter CJ, Wechsler H. Non-medical use of prescription stimulants among US college students: Prevalence and correlates from a national survey. Addiction. 2005; 99: 96-106.

22. Pettit ML, DeBarr KA. Perceived stress, energy drink consumption, and academic performance among college students. Journal of American College Health. 2011; 59: 335-341.

23. Teter CJ, McCabe SE, Cranford JA, Boyd CJ, Guthrie SK. Prevalence and motives for illicit use of prescription stimulants in an undergraduate studen population. Journal of American College Health. 2010; 53: 253-262.

24. Arria AM, Caldeira KM, Kasperski SJ, O'Grady KE, Vincent KB, Griffiths RR, et al. Increased alcohol consumption, nonmedical prescription drug use, and illicit drug use are associated with energy drink consumption among college students. Journal of Addiction Medicine. 2010; 4: 74-80.

25. Lorant V, Nicaise $P$, Soto VE, d'Hoore W. Alcohol drinking among college students: College responsibility for personal troubles. BMC Public Health. 2013

26. Bryant JB, Darkes J, Rahul C. College students' compensatory eating and behaviors in response to alcohol consumption. Journal of American College Health. 2012; 60: 350-356.

27. Giles SM, Champion H, Sutfin EL, McCoy TP, Wagoner K. Calorie restriction on drinking days: An examination of drinking consequences among college students. Journal of American College Health. 2009; 57: 603-609.

28. Galambos NL, Dalton AL, Maggs, JL. Losing sleep over it: Day variation in sleep quantity and quality in Canadian students' first semester of university. Journal of Research on Adolescence. 2009; 19: 741-761.

29. Singleton RA, Wolfson AR. Alcohol consumption sleep, and academic performance among college students. Journal of Studies on Alcohol and Drugs. 2009; 70: 355-363.

30. Deliens T, Clarys P, De Bourdeaudhuij I, Deforche B. Determinants of eating behavior in university students: A qualitative study using focus group discussions. BMC Public Health. 2014.

31. Thiagarajah K, Torabi MR. Irregular breakfast eating and associated health behaviors: A pilot study among college students. The Health Educator. 2009; 41: 4-10.

32. LaCaille LJ, Dauner KN, Krambeer RJ, Pedersen J. Psychosocial and environmental determinants of eating behaviors, physical activity, and weight change among college students: A qualitative analysis. Journal of American College Health. 2011; 59: 531-538.

33. Pauline JS. Physical activity behaviors, motivation, and self-efficacy among college students. College Student Journal. 2013; 47: 64-74

34. Zunhammer M, Eichammer P, Busch V. Sleep quality during exam stress The role of alcohol, caffeine and nicotine. PLoS One. 2014; 9.

35. Onyper SV, Thacher PV, Gilbert JW, Gradess SG. Class start times, sleep and academic performance in college: A path analysis. Chronobiology International. 2012; 29: 318-335.

36. Vinha D, Cavalcante JA, Andrade MMM. Sleep-wake patterns of student workers and non-workers. Biological Rhythm Research. 2002; 33: 417-426.

37. Machado ERS, Varella VBR, Andrade MMM. The influence of study schedules and work on the sleep-wake cycle of college students. Biological Rhythm Research. 1998; 29: 578-584.

38. Clegg-Kraynok MM, McBean AL, Montgomery-Downs HE. Sleep quality and characteristics of college students who use prescription psychostimulants nonmedically. Sleep Medicine 2011; 12: 598-602.

39. Mayo Clinic. Caffeine: how much is too much?. 2016.

40. Mcllvain GE, Noland MP, Bickel R. Caffeine consumption patterns and beliefs of college freshmen. American Journal of Health Education. 2011; 42: 235244.

41. Lohsoonthorn V, Khidir H, Casillas G, Lertmaharit S, Tadesse MG, Pensuksan WC, et al. Sleep quality and sleep patterns in relation to consumption of energy drinks, caffeinated beverages and other stimulants among Thai college students. Sleep and Breathing. 2013; 17: 1017-1028.

42. Wells TT, Cruess DG. Effects of partial sleep deprivation on food consumption and food choice. Psychology and Health. 2006; 21: 79-86.

43. Kredlow MA, Capozzoli MC, Hearon BA, Calkins AW, Otto MW. The effects of physical activity on sleep: A meta-analytic review. Journal of Behavioral Medicine. 2014; 38: 427-449.

44. Wu X, Tao S, Zhang Y, Tao F. Low physical activity and high screen time can increase the risks of mental health problems and poor sleep quality among Chinese college students. PLoS One. 2015; 10

45. Wyatt HR, Grunwald GK, Mosca CL, Klem ML, Wing RR, Hill JO. Long-term weight loss and breakfast in subjects in the national weight control registry. Obesity Research. 2002; 10: 78-82.

46. Buysse DJ, Reynolds CF, III Monk TH, Berman SR, Kupfer DJ. The Pittsburgh sleep quality index: A new instrument for psychiatric practice and research. Psychiatry Research. 1988; 28: 193-213.

47. Fortunato VJ, LeBourgeois MK, Harsh J. Development of a five-dimensional measure of adult sleep quality. Educational and Psychological Measurement. 2007; 68: 488-514

48. Steptoe A, Pollard, TM. Development of a measure of the motives underling the selection of food: The food choice questionnaire. Appetite. 1995; 25: 267 284

49. Copeland JL, Kowalski KC, Donen RM, Tremblay MS. Convergent validity of the physical activity questionnaire for adults: The new member of the PAQ family. Journal of Physical Activity and Health, 2005; 2: 216-229.

50. Tabachnick BG, Fidell LS. Using multivariate statistics $\left(6^{\text {th }}\right.$ ed.). Upper Saddle River. NJ: Pearson. 2013

51. National Sleep Foundation. How much sleep do we really need?. 2016.
Austin J Sleep Disord - Volume 4 Issue 1 - 2017

ISSN : 2471-0415 | www.austinpublishinggroup.com

Campsen et al. (C) All rights are reserved
Citation: Campsen NA and Buboltz WC. Lifestyle Factors' Impact on Sleep of College Students. Austin J Sleep Disord. 2017; 4(1): 1028. 